\title{
Hydraulic Characteristics and Suspended Sediment Loads during Spring Breakup in Several Streams Located on the National Petroleum Reserve in Alaska, USA
}

\author{
Horacio Toniolo ${ }^{1 *}$, Dragos Vas ${ }^{2}$, Peter Prokein ${ }^{3}$, Richard Kenmitz ${ }^{4}$, Erica Lamb ${ }^{2}$, Dave Brailey ${ }^{5}$ \\ ${ }^{1}$ Civil and Environmental Engineering Department, University of Alaska Fairbanks, Fairbanks, USA; ${ }^{2}$ Water and Environmental \\ Research Center, University of Alaska Fairbanks, Fairbanks, USA; ${ }^{3}$ Institute of Northern Engineering, University of Alaska Fair- \\ banks, Fairbanks, USA; ${ }^{4}$ Bureau of Land Management, Arctic Field Office, Fairbanks, USA; ${ }^{5}$ Brailey Hydrologic Consultants, An- \\ chorage, USA. \\ Email: *hatoniolo@alaska.edu
}

Received January $12^{\text {th }}, 2013$; revised April $6^{\text {th }}, 2013$; accepted April 27 $7^{\text {th }}, 2013$

Copyright (C) 2013 Horacio Toniolo et al. This is an open access article distributed under the Creative Commons Attribution License, which permits unrestricted use, distribution, and reproduction in any medium, provided the original work is properly cited.

\begin{abstract}
This article presents results from a broad field campaign involving discharge and surface-water slope measurements, water sampling, and longitudinal river-bed profile surveys. During the spring breakup of 2011, fieldwork was carried out in several pristine streams located in the National Petroleum Reserve in Alaska; the studied streams cover two main regions: 1) foothills (Ikpikpuk River, Seabee Creek, Prince Creek, and Otuk Creek); 2) coastal plain (Fish Creek, Judy Creek, and Ublutuoch River). Reported data includes basic geometric and hydraulic characteristics such as channel width and depth, cross-sectional area, average velocity, friction factor, shear stress, suspended sediment concentrations from autosamplers and grab samples, and dune dimensions and steepness ratios. The measured discharge in different streams ranged from 2 to $853 \mathrm{~m}^{3} / \mathrm{s}$, which corresponded to post-breakup and near peak conditions, respectively. The temporal variation of Manning's $n$ was in phase with measured discharge, with high values of $n$ associated with the presence of floating ice during the measurements. Calculations indicate that sediment particle sizes $\leq 2 \mathrm{~mm}$ moved during the measurements. In general, variations in discharge were accompanied by changes in suspended sediment concentrations.
\end{abstract}

Keywords: Suspended Sediment Concentration; Bedforms; Resistance Coefficient; Spring Breakup; Arctic Hydrology

\section{Introduction}

The While the existing literature describing basic hydraulic and sedimentological characteristics in major rivers and tributaries in temperate regions is vast (see for instance, case studies presented in books [1-5] and research articles [6-9], among many others), the existing published data on streams located in extreme cold-weather settings is somewhat limited [5,10-13]. The methodologies used in studies performed in moderate environments ranged from simple to complex techniques involving single to multiple measurements. Studies in cold regions were, in general, characterized by simple methods and single measurements. Furthermore, only partial literature is available in Arctic Alaska [14-16] and Ettema and Kempema (2012) [17] indicate that "detailed information addressing river-ice effects on alluvial ch-

"Corresponding author. annels is quite sparse". Compounding this lack of data are indications in current research of reductions in field data collection efforts in high-latitude regions [18]. The main reasons for the scarcity of literature in cold regions are the adverse climatic conditions, short timeline of hydrologic events, and fieldwork logistics. Thus, any new published data will directly or indirectly benefit the research community.

The North Slope of Alaska, like most Arctic environments, maintains its pristine condition. However, as an increase in planning activities for infrastructure related to oil and gas exploration and production occurs, the need for basic hydro-sedimentologic data for streams in this region becomes evident. This information is crucial for designing new infrastructure, such as river crossings and permitting processes.

This article presents results from an extensive fieldwork campaign carried out during the 2011 spring 
breakup, which is typically the largest hydrologic event of the year [14], in several streams located on the National Petroleum Reserve in Alaska (NPR-A). Specifically, field activities consisted of discharge measurements, surveying longitudinal riverbed profiles, surface-water slope measurements, and water sampling to estimate suspended sediment concentration. In addition, cross-sectional roughness coefficients, bed shear stress, and suspended sediment loads are reported.

\section{Study Sites}

The study sites are located in the NPR-A, an area established as a petroleum reserve in 1923; currently the NPR-A is under the jurisdiction of the Bureau of Land Management (BLM). The total surface of this extensive region is approximately $92,000 \mathrm{~km}^{2}$, which is divided into three main planning areas: the Northeast with 19,000 $\mathrm{km}^{2}$, the Northwest with $36,000 \mathrm{~km}^{2}$, and the South with $37,000 \mathrm{~km}^{2}$ of public land [19].

Field measurements were carried out on seven pristine streams distributed in two main topographic regions: the foothills and coastal plain. Streams located in the foothills areas are: Ikpikpuk River, Seabee Creek, Prince Creek, and Otuk Creek; while streams sited on the coastal plain are: Fish Creek, Judy Creek, and Ublutuoch River. These sites were established by BLM approximately ten years ago. Water level data is collected at all the stations, while basic weather data (i.e., air temperature, precipitation, wind speed and wind direction) is also collected at some stations. Current conditions are available online at http://ine.uaf.edu/werc/projects/npra-hydrology. It is important to mention that all sites are only accessible by helicopter, which generally poses a serious limitation to fieldwork activities due to unreliable weather conditions in the area. Figure 1 shows the general location and watershed configuration of study sites. Additionally, Table 1 provides the coordinates of river gauging stations as well as the contributing watershed areas. These watersheds have snowmelt-dominated hydrographs. However, it was indicated that summer rainstorms could produce higher peak flows in watersheds located in the foothills region [20]; watersheds in the coastal plain seldom respond to summer precipitation with high peak flows [21].

\section{Methods}

The goal of field activities was to collect basic data in order to characterize the hydrosedimentological conditions in each stream (i.e., discharge, channel dimensions, longitudinal bed profiles, water-surface slope, and suspended sediment concentration). Restrictions such as weather and logistics, however, limited the activities that could be performed at each site. As a result the collected data sets differ from stream to stream.

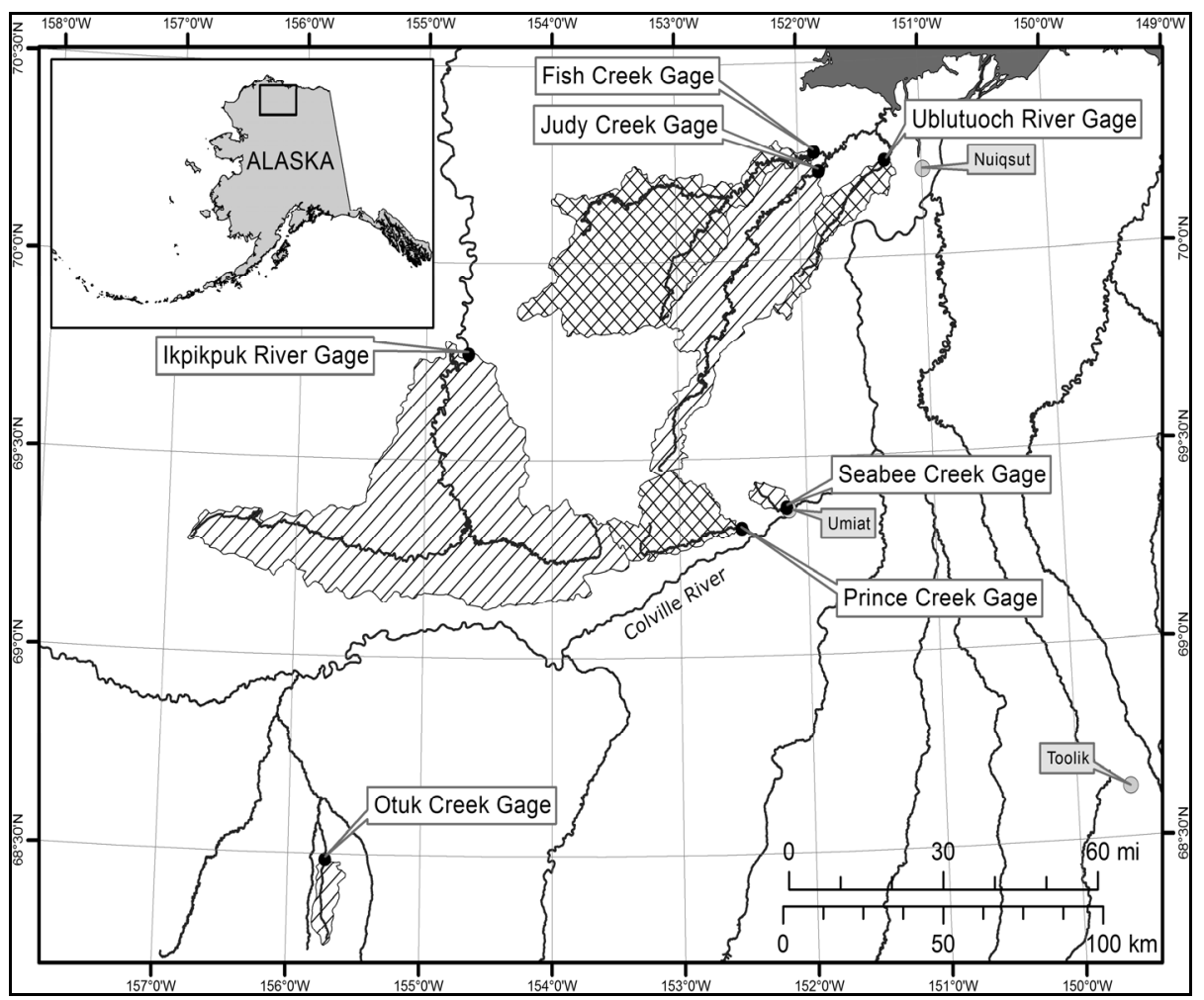

Figure 1. Study site locations and watershed delineations inside NPR-A. 
Table 1. Site gauge locations and contributing watershed areas.

\begin{tabular}{cccc}
\hline Site & Latitude $(\mathrm{N})$ & Longitude $(\mathrm{W})$ & Area $\left(\mathrm{km}^{2}\right)$ \\
\hline Fish Creek & 70.27 & 151.869 & 2088 \\
Ikpikpuk River & 69.767 & 154.663 & 4391 \\
Judy Creek & 70.22 & 151.835 & 1605 \\
Otuk Creek & 68.486 & 155.717 & 146 \\
Prince Creek & 69.322 & 152.515 & 574 \\
Seabee Creek & 69.373 & 152.158 & 59 \\
Ublutuoch River & 70.243 & 151.298 & 331 \\
\hline
\end{tabular}

Discharge measurements were completed using a Teledyne RDI Rio Grande $1200 \mathrm{KHz}$ and a StreamPro $2000 \mathrm{KHz}$ Acoustic Doppler Current Profiler (ADCP). One of the ADCP units, the Rio Grande, was deployed from a motorized inflatable raft; the other unit, the StreamPro, was installed on a $3 \mathrm{~m}$ Aire inflatable kayak. The boats were also equipped with a radio and a NovAtel GPS rover station, while a second NovAtel GPS was used as an onshore base station. This GPS system provided Real-Time Kinematic (RTK) positioning to the ADCP. The communication between the field computer, ADCP, and GPS was established via a Parani Bluetooth system coupled with directional and omni-directional antennas. The measurements in all streams were performed following guidelines established by the United States Geological Service [22] for measurements using an ADCP (i.e., compass calibration, four river transects, and a $5 \%$ coefficient of variation between individual discharge measurements and average discharge value, $Q$ ). Water level readings were taken on local staff gauges installed on the rivers' banks. The staff gauges were referenced to arbitrary datums established on each site.

Daily suspended-sediment samples were taken with an Isco 3700 and a Sigma 900 Portable Autosamplers on the Prince and Seabee Creeks respectively; grab samples were taken on the other streams (10 samples). The automated samplers were programmed to collect a single sample per day, with the water intake located approximately $15 \mathrm{~cm}$ above the riverbed. Grab samples were gathered in the center of the stream, approximately 50 $\mathrm{cm}$ below the water surface. Water samples were filtered through Whatman GF/C glass microfiber filters with particle retention of $1.2 \mu \mathrm{m}$. The suspended sediment concentrations (SSC) were calculated following the ASTM standard D 3977 - 97, Method B [23].

The percentage of organic matter in each sample was then determined using ASTM Standard 2974, Method C [24], in which samples are placed in a muffle furnace at $440^{\circ} \mathrm{C}$ for twelve hours. The analyses were conducted at the University of Alaska Fairbanks Water and Environmental Research Center. Suspended sediment load, $Q_{s}$, is defined as

$$
Q_{s}=(S S C) Q
$$

it should be noted that $Q_{s}$ in Equation (1) would be accurate if SSC represents the sediment concentration of the entire river cross-section, which would be obtained from a single or multiple samples integrated through the water depth. In this article, however, $S S C$ values used in Equation (1) were calculated from point samples. Thus, the values reported in Results should be considered as rough approximations. Nevertheless, it is argued that these values still provide valuable information for the studied streams. Relationships between point samples collected with automated samplers and integrated samples are being investigated as part of ongoing research efforts and are outside the scope of this manuscript.

A Zeiss level and a graduated rod were used to measure the water-surface slope in some of the streams, following traditional surveying methodologies. Measurements were carried out on the Ikpikpuk, Fish, Judy, and Ublutuoch streams concurrently with some of the discharge measurements. These values were used to estimate the streams' roughness coefficient, following a methodology previously reported [16], which is described in the following paragraphs.

The ADCP-generated measurements of channel area, width, and velocity were used along with the water- surface slope measurements to back-calculate the Manning's roughness coefficient, $n$, given by

$$
n=\frac{1}{U} H^{2 / 3} S^{1 / 2}
$$

where $U$ denotes the cross-sectional average velocity; $H$ denotes the average depth, and $S$ denotes the water-surface slope. The average cross-sectional depth is obtained as

$$
H=\frac{A}{B}
$$

where $A$ denotes the cross-sectional area and $B$ denotes the channel width. Bed shear stress, $\tau_{b}$, is calculated using the following relation

$$
\tau_{b}=g \rho H S
$$

where $g$ denotes gravity, and $\rho$ denotes water density. In addition, the Froude number, $F_{r}$, was calculated by the following equation:

$$
\mathrm{F}_{\mathrm{r}}=\frac{\mathrm{U}}{\sqrt{\mathrm{Hg}}}
$$

the dimensionless Shield's parameter [5], $\theta$, is defined as 


$$
\theta=\frac{\tau_{b}}{\left(\gamma_{\mathrm{w}} S_{s} d_{s}\right)}
$$

where $\gamma_{w}$ denotes specific weight of water; Ss denotes the submerged specific gravity, which is approximately 1.65 for natural sands; $d_{s}$ denotes the representative sediment grain size. This parameter indicates if a given sediment size would move or remain at rest based on the shear stress acting on the particle.

It should be noted that Equations (2)-(6) assume normal flow conditions, whereas the prevailing conditions during the fieldwork somewhat deviated from this principle. Thus, these equations provide a first approximation to describe the streams' hydraulic characteristics at the study sites. Similar equations were used by other researchers [14,16,25-28] to characterize flow parameters in conditions that were markedly different from those assumed in Equations (2)-(6). Specifically, these equations were used in floods and flood modeling analyses.

Longitudinal river-bed profiles were surveyed along the thalweg on the Ikpikpuk, Prince, Judy, and Ublutuoch Streams. In addition, a longitudinal profile was gathered for comparison purposes on the Colville River near Umiat. Major bedforms (dunes) were identified in the profiles and basic geometric dimensions (i.e., wavelength, $\lambda$, and height, $\Delta$ ) were measured. Then the steepness ratio, which is defined as $\Delta / \lambda$ of each dune was calculated. Due to the natural variability of dunes in rivers the minimum, average, and maximum steepness ratios were computed. In general, the steepness ratio provides information on the river's hydraulic adjustment to varying discharge. Specifically, bedforms are the main contributors of form resistance [5].

\section{Results}

While the manuscript is focused on hydro-sedimentologic conditions in the studied streams, preliminary work was done to establish basic weather conditions in the area during the 2010-2011 winter season. Specifically the accumulated freezing degree days were calculated for two stations located at the opposite ends of an imaginary north-south line (i.e., Fish and Otuk Creeks). Computed values, from 15 September 2010 to 15 June 2011, were 4311 and $3662^{\circ} \mathrm{C}$-days for Fish and Otuk Creeks, respectively. These values show colder temperatures in the northern part of the study area. A detailed analysis of meteorological variables such as air temperature, precipitation, wind speed, and wind direction for all stations in the region is outside the scope of this work, and would in fact constitute a standalone article.

The primary source of water during breakup in streams located in NPR-A is runoff due to snowmelt, while rain- fall events during this period constitute the secondary source of water. Spatially distributed values of end-ofwinter snow water equivalent (SWE) would provide insights on the amount of water available for runoff on the watershed. Unfortunately, no ground measurements of SWE were available for the study area. Measured rainfall was insignificant during the 2011 breakup period.

Table 2 shows the ice conditions during the measurements and data collected in the field, such as discharge, channel width, cross-sectional area, local staff gauge reading, and water slope from Fish, Ikpikpuk, Judy and Ublutuoch streams. Subsequent columns in the table represent parameters computed using field data. For instance, Equations (2)-(5) were used to populate columns $10,9,11$, and 12 respectively. The dimensionless Shield's parameter is included in column 13. A sediment size of 2 $\mathrm{mm}$, which is the limit of coarse sand, was used in the calculation of $\theta$. The Shield's parameter, also known as dimensionless bed shear stress, values were above the critical value during the field campaign. Thus, one could expect that sediment particle sizes $\leq 2 \mathrm{~mm}$ moved during the measurements. Manning's $n$ (column 10) modifications were directly related with discharge variations. The flow regime in all measurements was subcritical (i.e., $F_{r}$ $<1)$.

Daily suspended sediment concentrations (from samples collected with the autosamplers) are shown in Figures $\mathbf{2}$ and $\mathbf{3}$ for Seabee and Prince Creeks, respectively. In addition, daily discharge and suspended sediment loads are shown in these figures.

Discharge values were estimated from pressure transducer data and rating curves developed for the sites. A comparison between $S S C$ in both figures indicates that suspended sediment concentrations in Prince Creek were, in general, smaller than concentrations in Seabee Creek. As evidenced by these figures, the variations in suspended sediment concentration in both streams partially matched the temporal variation of discharge. Additionally, these figures indicate that sediment could be unavailable (frozen) during the early stages of breakup.

Table 3 shows the suspended sediment concentrations from grab samples collected in the Fish, Ikpikpuk, Judy, Otuk, and Ublutuoch streams. In addition, measured discharge and calculated suspended sediment load are included in the table. Data indicates that sediment concentrations in Fish Creek increased nearly $450 \%$ in a 5-day period, while discharge only increased $20 \%$. The changes in SSC and discharge were around $60 \%$ in Judy Creek. Sediment concentrations remained constant in Ublutuoch River.

Basic dune dimensions (i.e., wavelength and height) and steepness ratios in the vicinity of the gauging sites for Prince, Ikpikpuk, Judy, and Ublutuoch streams are 
Table 2. Geometric and hydraulic characteristics.

\begin{tabular}{|c|c|c|c|c|c|c|c|c|c|c|c|c|}
\hline Stream & Date & $\underset{\left(\mathrm{m}^{3} / \mathrm{s}\right)}{Q}$ & $\begin{array}{c}B \\
(\mathrm{~m})\end{array}$ & $\begin{array}{c}A \\
\left(\mathrm{~m}^{2}\right)\end{array}$ & $\begin{array}{l}\text { Staff gauge } \\
\text { (ft) }\end{array}$ & $S$ & $\begin{array}{c}U=Q / A \\
(\mathrm{~m} / \mathrm{s})\end{array}$ & $\begin{array}{c}H=A / B \\
\quad(\mathrm{~m})\end{array}$ & $n$ & $\begin{array}{c}\text { Tao } \\
\left(\mathrm{N} / \mathrm{m}^{2}\right)\end{array}$ & Fr & $\begin{array}{l}\text { Shield's } \\
\text { Parameter }\end{array}$ \\
\hline \multirow{3}{*}{ Ikpikpuk } & 29 May $2011^{[\mathrm{A}]}$ & 801.7 & 164.3 & 710.5 & 36.88 & 0.00019 & 1.1 & 4.32 & 0.032 & 8.06 & 0.17 & 0.25 \\
\hline & 31 May $2011^{[\mathrm{A}]}$ & 852.7 & 118.9 & 431.5 & 36.92 & 0.000741 & 2.0 & 3.63 & 0.033 & 26.39 & 0.33 & 0.82 \\
\hline & 3 June $2011^{[\mathrm{B}]}$ & 230.2 & 89.9 & 168.5 & 29.41 & 0.00022 & 1.4 & 1.87 & 0.017 & 4.05 & 0.32 & 0.12 \\
\hline \multirow{2}{*}{ Fish } & 2 June $2011^{[\mathrm{A}]}$ & 59.1 & 75.1 & 139.3 & 22.8 & 0.00009 & 0.4 & 1.85 & 0.034 & 1.64 & 0.10 & 0.05 \\
\hline & 7 June $2011^{[\mathrm{A}]}$ & 69.2 & 65.8 & 122.0 & 21.47 & 0.00032 & 0.6 & 1.85 & 0.048 & 5.82 & 0.13 & 0.18 \\
\hline \multirow{2}{*}{ Judy } & 2 June $2011^{[\mathrm{A}]}$ & 126.3 & 77.7 & 151.3 & 26.96 & 0.00052 & 0.8 & 1.95 & 0.043 & 9.93 & 0.19 & 0.31 \\
\hline & 7 June $2011^{[\mathrm{B}]}$ & 74.6 & 46.6 & 98.4 & 24.86 & 0.00031 & 0.8 & 2.11 & 0.038 & 6.42 & 0.17 & 0.20 \\
\hline \multirow{2}{*}{ Ublutuoch } & 2 June $2011^{[\mathrm{A}]}$ & 48.1 & 31.4 & 42.4 & 18.5 & 0.00108 & 1.1 & 1.35 & 0.035 & 14.30 & 0.31 & 0.44 \\
\hline & 7 June $2011^{[\mathrm{B}]}$ & 33.4 & 25.3 & 32.4 & 14.84 & 0.00083 & 1.0 & 1.28 & 0.033 & 10.44 & 0.29 & 0.32 \\
\hline
\end{tabular}

${ }^{[\mathrm{A}]}$ Floating ice. ${ }^{[\mathrm{B}]}$ Ice free conditions.

Table 3. Suspended sediment concentration and suspended sediment loads.

\begin{tabular}{|c|c|c|c|c|}
\hline Stream & Date & $\mathrm{SSC}(\mathrm{mg} / \mathrm{l})$ & $\mathrm{Q}\left(\mathrm{m}^{3} / \mathrm{s}\right)$ & Qss (g/s) \\
\hline Fish & $\begin{array}{l}2 \text { June } 2011 \\
5 \text { June } 2011 \\
7 \text { June } 2011\end{array}$ & $\begin{array}{l}19.61 \\
33.39 \\
88.49\end{array}$ & $\begin{array}{l}57.7 \\
56.6 \\
69.2\end{array}$ & $\begin{array}{l}1130.8 \\
1891.1 \\
6121.2\end{array}$ \\
\hline Ikpikpuk & 3 June 2011 & 72.66 & 230.2 & 16724.6 \\
\hline Judy & $\begin{array}{l}2 \text { June } 2011 \\
5 \text { June } 2011 \\
7 \text { June } 2011\end{array}$ & $\begin{array}{l}152.22 \\
186.55 \\
115.27\end{array}$ & $\begin{array}{c}126.3 \\
79.8 \\
74.6\end{array}$ & $\begin{array}{c}19225.8 \\
14886.7 \\
8599.4\end{array}$ \\
\hline Otuk & 4 June 2011 & 0.51 & 2.1 & 1.1 \\
\hline Ublutuoch & $\begin{array}{l}5 \text { June } 2011 \\
7 \text { June } 2011 \\
\end{array}$ & $\begin{array}{l}10.84 \\
10.93 \\
\end{array}$ & $\begin{array}{l}46.5 \\
33.2 \\
\end{array}$ & $\begin{array}{l}504.2 \\
363.4 \\
\end{array}$ \\
\hline
\end{tabular}

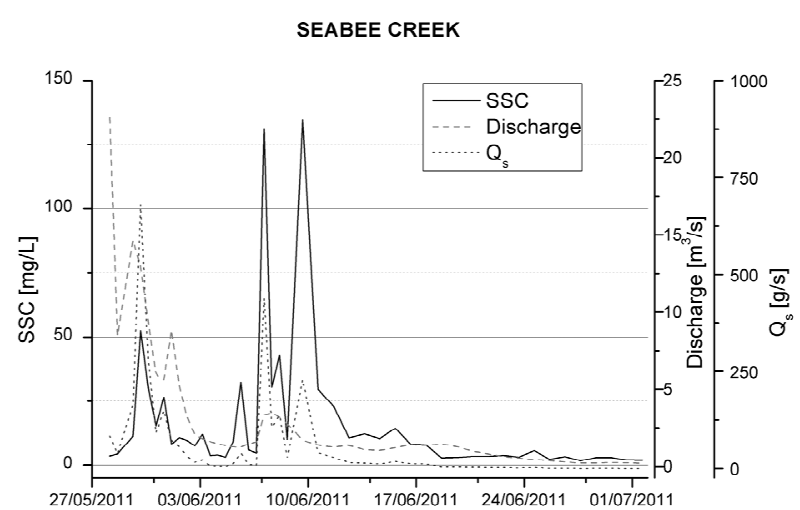

Figure 2. Suspended sediment concentration, discharge, and suspended sediment load. Seabee creek.

presented in Table 4. For comparison purposes, data from the Colville River, near Umiat is also included the table. Minimum, average, and maximum values are reported to represent the natural variability of dunes in rivers. Average wavelengths and heights in NPR-A streams ranged from 17 to $123 \mathrm{~m}$, and 0.3 to $1.1 \mathrm{~m}$, respectively, while similar parameters for the Colville River were 270 and $0.7 \mathrm{~m}$. Steepness ratios were consistently higher in NPR-A streams than in the Colville River. Figure 4 shows the longitudinal bed profile along the thalweg on Prince Cree; in this figure, several dunes can be identi-

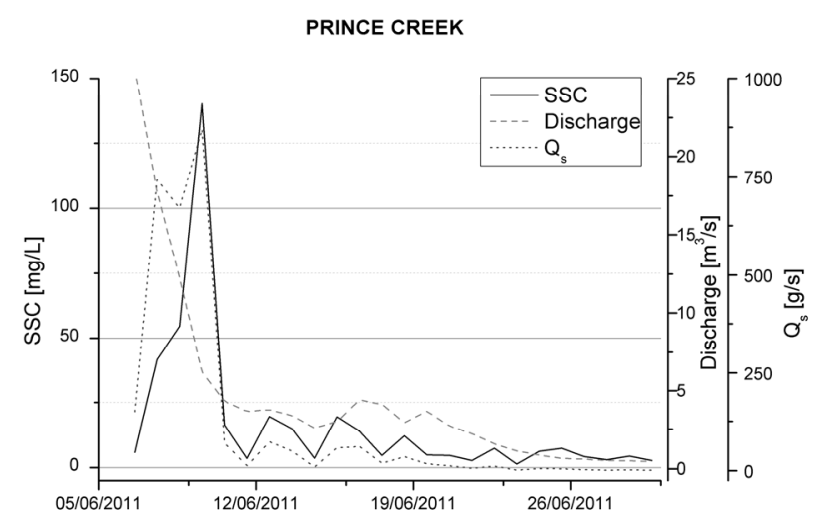

Figure 3. Suspended sediment concentration, discharge, and suspended sediment load. Prince creek.

fied. In addition, superimposed ripples (smaller bedforms) can be seen on top the dunes, especially on the left side of the figure. These smaller bedforms were not visible in all longitudinal profiles. Thus, no geometric details are presented.

\section{Discussion}

The presence of static and floating ice certainly modifies the stream flow conditions. For instance, anchor ice alters the available flow area and the bed roughness, 


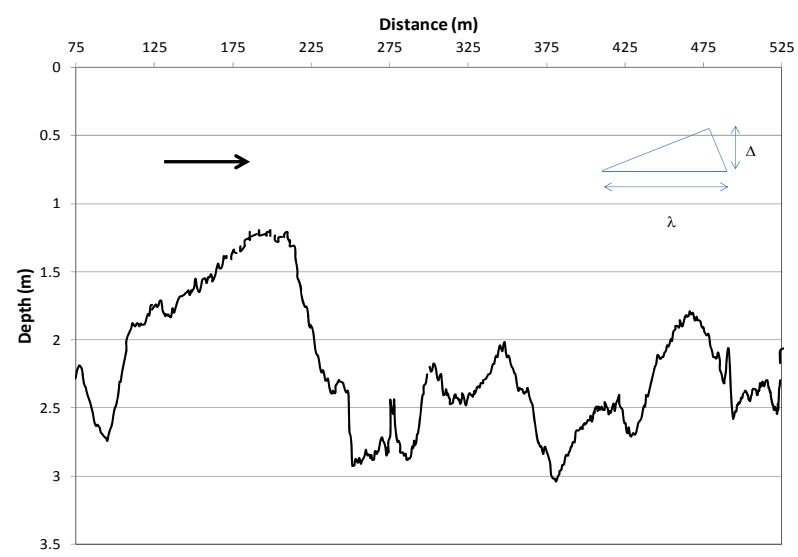

Figure 4. Longitudinal bed profile showing bedforms in Prince creek. Flow is from left to right. Inset indicates basic bedform dimensions.

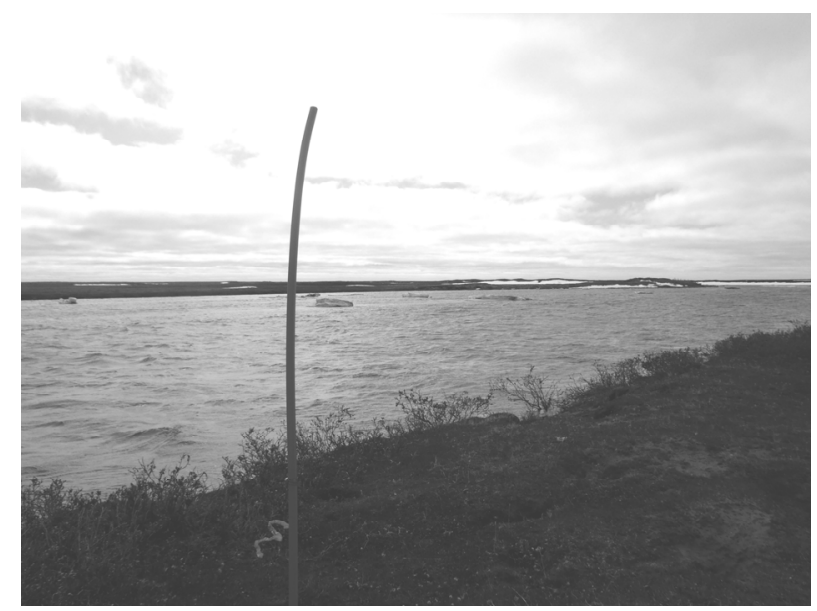

Figure 5. Fish creek. Blocks of floating ice moving downstream are visible in the channel. Flow direction is from right to left. 7 June 2011.

thereby affecting the overall roughness coefficient. Floating ice creates additional resistance on the water surface, potentially affecting the water-surface slope and Manning's $n$. The condition of continuous ice cover changes, in addition to the previous parameters, the hydraulic radius (essentially $H$ in Equation (3)). However, none of the reported discharge measurements were performed under ice cover. Floating ice conditions were present in most of the measurements shown in Table 2. Dimensions of ice blocks were highly variable, with representative values ranging from 5 to $10 \mathrm{~m}$ and 10 to $20 \mathrm{~m}$, for width and length respectively. The estimated thickness of moving ice ranged from 0.3 to $0.9 \mathrm{~m}$.

The temporal variation of Manning's $n$ in each stream (Table 2) was in phase with measured discharge. Additionally, high values of $n$ were associated with the presence of floating ice during the measurements. It is expected that ice floe added extra resistance to the flow,
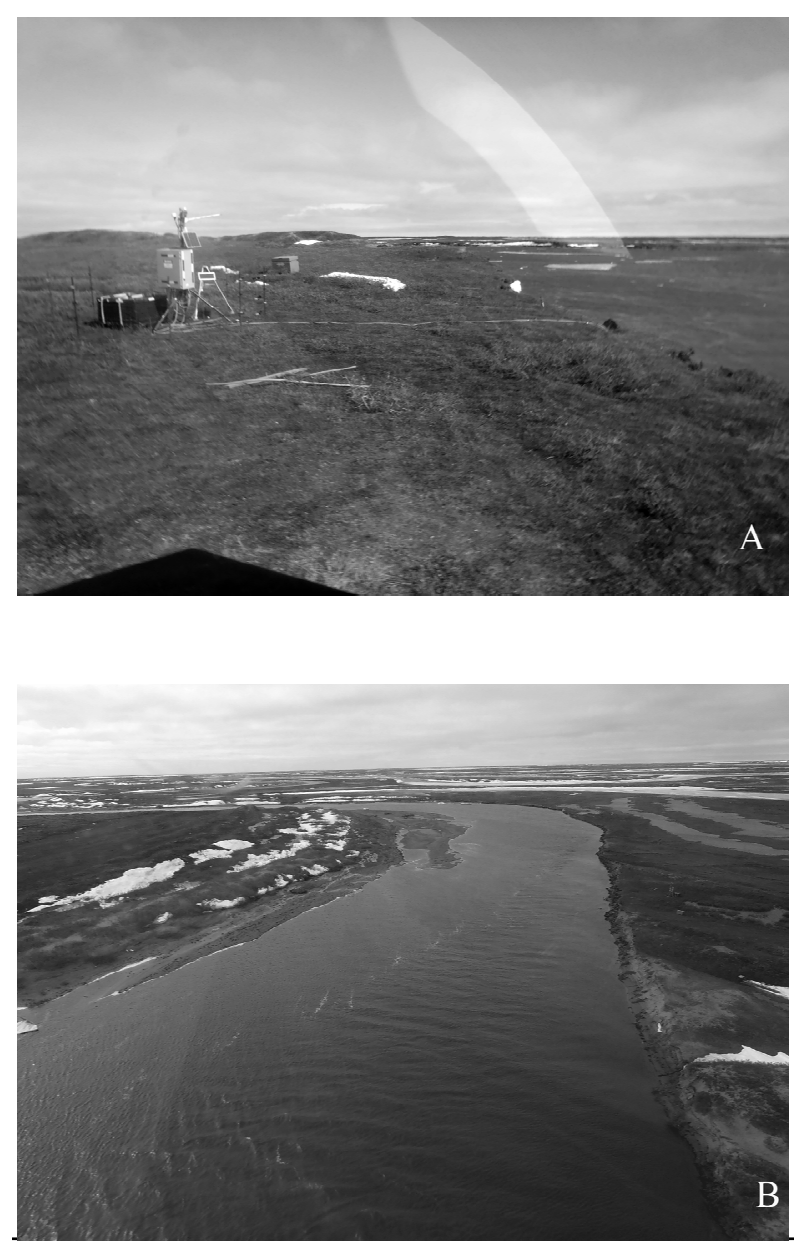

Figure 6. Judy creek. (A) Floating ice moving downstream (right side of the picture). Basic meteorological and water station installed at the site is also shown in the left side of the picture. Flow direction is into the page. 2 June 2011. (B) Free-ice channel. Flow direction is out of the page. 7 June 2011.

consequently increasing the $n$ value. Figures 5 and $\mathbf{6}$ show examples of ice moving downstream along the measurement reach in Fish and Judy Creeks, respectively.

The Shield's parameter (Table 2), when plotted in the Shield's diagram [5], indicates that coarse sand would move as bedload in all streams reported in this table. Fractions of finer sediments could be moved in suspendsion.

Data reported in Table 3 indicates that Judy Creek carried the maximum suspended sediment concentrations of measured streams, whereas the concentration in Otuk Creek was negligible at the time of sampling, which did not coincide with any other stream. It should be noted that due to logistics, sampling and measurements in Otuk were done after breakup (i.e., low discharge and near clear-water condition). Thus, no definitive conclusion 
Table 4. Bedform dimensions and steepness ratios.

\begin{tabular}{ccccccccccccc}
\hline Date & River & \multirow{2}{*}{ Q $\left(\mathrm{m}^{3} / \mathrm{s}\right)$} & \multicolumn{3}{c}{ Wavelength $(\mathrm{m})$} & \multicolumn{3}{c}{ Height $(\mathrm{m})$} & \multicolumn{3}{c}{ Steepness } \\
\hline & & & min & average & $\max$ & $\min$ & average & $\max$ & $\min$ & average & max \\
\hline 30 May 2011 & Prince & 187.7 & 93.8 & 123.2 & 158.0 & 0.9 & 1.1 & 1.6 & 0.008 & 0.009 & 0.010 \\
3 June 2011 & Ikpikpuk & 230.2 & 36.2 & 48.2 & 70.3 & 0.2 & 0.4 & 0.9 & 0.004 & 0.009 & 0.018 \\
7 June 2011 & Judy & 74.6 & 13.7 & 17.4 & 21.7 & 0.2 & 0.3 & 0.6 & 0.013 & 0.019 & 0.028 \\
7 June 2011 & Ublutuoch & 33.2 & 33.8 & 45.5 & 56.3 & 0.5 & 0.5 & 0.6 & 0.010 & 0.012 & 0.016 \\
30 May 2011 & Colville & $\left.6597.8^{*}\right)$ & 192.7 & 270.4 & 353.2 & 0.5 & 0.7 & 1.0 & 0.002 & 0.003 & 0.004 \\
\hline
\end{tabular}

${ }^{(*)}$ Estimated value - source USGS.

can be made on the Otuk Creek sediment load. Daily SSC plotted in Figure 3 seems to indicate that sediment supply could be limited in the Prince watershed.

Available data in Table 4 indicates an inverse relation between dune steepness and discharge. It should be noted that longitudinal profiles in NPR-A streams did not coincide with peak discharges in each stream. In addition, the survey on the Colville River was conducted one day after the river peaked on 29 May $2011\left(Q_{\text {peak }}=7840 \mathrm{~m}^{3} / \mathrm{s}-\right.$ from USGS site http://waterdata.usgs.gov/ak/n wis/dv/? site_no $=15875000 \&$ agency_cd $=$ USGS\&referred_module $=\mathrm{sw})$. Thus, values reported in Table 4 should not be used to estimate steepness during peak flow. Additional surveys should be performed during high and low flows.

It is acknowledged here that the information collected in the field was limited, particularly water samples. However, the results presented here constitute the first step in characterizing pristine rivers in NPR-A. Future work will include additional data collection efforts to develop relationships between SSC calculated from autosamplers and integrated samples collected at several locations along the river cross-section. Nevertheless, these types of activities can be challenging in Arctic environments.

\section{Conclusions}

An extensive and logistically complicated field campaign during spring breakup was carried out in several pristine streams located in the National Petroleum Reserve in Alaska. Several instruments were used in the field. Using the information gathered during fieldwork activities, we present the initial hydraulic and sedimentological data from these streams. Specifically, we report: discharge, basic geometric dimensions (channel width, cross-sectional area, and average depth), water-surface slope, Manning's friction factor, Shield's parameter, suspended sediment concentration, suspended sediment loads, and dune's steepness ratio.

The temporal variation of Manning's $n$ was in phase with measured discharge; high values of $n$ were also associated with the presence of floating ice during the measurements. Dimensionless Shield's parameter, also known as dimensionless bed shear stress, values corresponding to $d_{s}=2 \mathrm{~mm}$ (coarse sands) were above the critical value during the field campaign. Thus, one could expect that sediment particle sizes $\leq 2 \mathrm{~mm}$ moved during the measurements.

In general, variations in discharge were accompanied by changes in suspended sediment concentrations. The wavelength of dunes in NPR-A streams were smaller than in the Colville River near Umiat.

Reported data would provide basic information for designing new infrastructure in the NPR-A area, such as river crossings. It would be also valuable for permitting purposes.

\section{Acknowledgements}

This work was funded by the Bureau of Land Management and US Fish and Wildlife Service, under contracts L09AC15923 and 70181BT021 to the University of Alaska Fairbanks.

\section{REFERENCES}

[1] K. Pye, "Sediment Transport and Depositional Processes," Blackwell, Oxford, 1994, 397 Pages.

[2] H. Chang, "Fluvial Processes in River Engineering," Krieger, Malabar, 2002, 432 Pages.

[3] P. Julien, "River Mechanics," Cambridge University Press, Cambridge, 2002, 433 Pages. doi:10.1017/CBO9781139164016

[4] J. Bridge, "Rivers and Floodplains: Form, Processes, and Sedimentary Record," Blackwell, Oxford, 2003, 491 Pages.

[5] ASCE, "Sedimentation Engineering: Processes, Measurements, Modeling and Practice," In: M. Garcia, Ed., Manual 110, American Society of Civil Engineers, Reston, 2008, 1132 Pages.

[6] M. Hassan, "Scour, Fill and Burial Depth of Coarse Material in Gravel Bed Streams," Earth Surface Processes 
and Landforms, Vol. 15, No. 4, 1990, pp. 341-356. doi:10.1002/esp.3290150405

[7] D. Hicks and P. Mason, "Roughness Characteristics of New Zealand Rivers," New Zealand National Institute of Water and Atmospheric Research, Auckland, 1991, 329 Pages.

[8] O. Navratil, M. Albert, E. Herouin and J. Gresillon, "Determination of Bankfull Discharge Magnitude and Frequency: Comparison of Methods on 16 Gravel-Bed River Reaches," Earth Surface Processes and Landforms, Vol. 31, No. 11, 2006, pp. 1345-1363. doi:10.1002/esp.1337

[9] U. Ji, P. Julien and S. Park, "Sediment Flushing at the Nakdong River Estuary Barrage," Journal of Hydraulic Engineering, ASCE, Vol. 137, No. 11, 2011, pp. 15221535. doi:10.1061/(ASCE)HY.1943-7900.0000395

[10] G. Ashton, "River and Lake Ice Engineering," Water Resources Publications, Littleton, 1986, 485 Pages.

[11] T. Prowse, "Suspended Sediment Concentration during River Ice Breakup," Canadian Journal of Civil Engineering, Vol. 20, No. 5, 1993, pp. 872-875. doi:10.1139/193-113

[12] S. Beltaos and B. Burrel, "Suspended Sediment Concentration in the S. John River during Ice Breakup," Proceedings of Canadian Society of Civil Engineers, Annual Conference, Toronto, 7-10 June 2000, pp. 235-242.

[13] A. Shiklomanov, T. Yakovlera, R. Lammers, I. Karasev, C. Vorosmarty and E. Linder, "Cold Region Reiver Discharge Uncertainty-Estimates from Large Russian Rivers," Journal of Hydrology, Vol. 326, No. 1-4, 2006, pp. 231-256. doi:10.1016/j.jhydrol.2005.10.037

[14] J. McNamara, J. Oatley, D. Kane and L. Hinzman, "Case Study of a Large Summer Flood on the North Slope of Alaska: Bedload Transport," Hydrology Research, Vol. 39, No. 4, 2008, pp. 299-308. doi:10.2166/nh.2008.006

[15] M. Mikhailova, "Hydrological Processes at an Arctic River Mouth: Case Study of the Colville River, Alaska, USA," Water Resources, Vol. 36, No. 1, 2009, pp. 26-42. doi:10.1134/S0097807809010035

[16] H. Toniolo, J. Derry, K. Irving and W. Schnabel, "Hydraulic and Sedimentological Characterizations of a Reach on the Anaktuvuk River, Alaska," Journal of Hydraulic Engineering, ASCE, Vol. 136, No. 11, 2010, pp. 935-939. doi:10.1061/(ASCE)HY.1943-7900.0000265

[17] R. Ettema and E. Kempema, "River-Ice Effects on GravelBed Channels," In: M. Church, P. Biron and A. Roy, Eds., Gravel-Bed Rivers: Processes, Tools, Environments, WileyBlackwell, Oxford, 2012, pp. 525-540.

[18] T. Prowse, K. Alfredsen, S. Beltaos, B. Bonsal, C. Duguay,
A. Korhola, J. McNamara, V. Warwick, V. Vuglinsky and G. Weyhenmeyer, "Arctic Freshwater Ice and Its Climatic Role," Ambio, Vol. 40, No. 1, 2011, pp. 46-52. doi:10.1007/s13280-011-0214-9

[19] E. Attanasi and P. Freeman, "Economic Analysis of the 2010 US Geological Survey Assessment of Undiscovered Oil and Gas in the National Petroleum Reserve in Alaska," US Geological Survey Open-File Report 2011-1103, 2011, 64 Pages.

[20] D. Kane, J. McNamara, D. Yang, P. Olsson and R. Gieck, "An Extreme Rainfall/Runoff Event in Arctic Alaska," Journal of Hydrometeorology, Vol. 4, No. 6, 2003, pp. 1220-1228. doi:10.1175/1525-7541(2003)004<1220:AEREIA $>2.0$.C $\underline{\mathrm{O} ; 2}$

[21] L. Bowling, D. Kane, R. Gieck, L. Hinzman and D. Lettenmaier, "The Role of Surface Storage in a Low-Gradient Arctic Watershed," Water Resources Research, Vol. 39, No. 4, 2003, 1087. doi:10.1029/2002WR001466

[22] D. Mueller and C. Wagner, "Measuring Discharge with Acoustic Doppler Current Profilers from a Moving Boat," USGS techniques and Methods 3A-22, 2009, 72 Pages.

[23] ASTM, "Standard D3977-97," ASTM Website, 2009. www.astem.org

[24] ASTM, "Standard C136-06," ASTM Website, 2010. www.astem.org

[25] E. Gaume, M. Livet, M. Desbordes and J. Villeneuve, "Hydrological Analysis of the River Aude, France, Flash Flood on 12 and 13 November 1999," Journal of Hydrology, Vol. 286, No. 1-4, 2004, pp. 135-154. doi:10.1016/j.jhydrol.2003.09.015

[26] M. Rico, G. Benito and A. Barnolas, "Combined Paleoflood and Rainfall-Runoff Assessment of Mountain Floods (Spanish Pyrenees)," Journal of Hydrology, Vol. 245, No. 1-4, 2001, pp. 59-72. doi:10.1016/S0022-1694(01)00339-0

[27] R. Kidson, K. Richards and P. Carling, "Hydraulic Model Calibration Using A Modern Flood Event: The Mae Chaem River, Thailand," Proceedings of the PHEFRA Workshop, Barcelona, 16-19 October 2002, pp. 171-176.

[28] S. Samarasinghea, H. Nandalalb, D. Weliwitiyac, J. Fowzed, M. Hazarikad and S. Samarakoond, "Application of Remote Sensing and GIS for Flood Risk Analysis: A Case Study at Kalu-Ganga River, Sri Lanka," International Archives of the Photogrammetry, Remote Sensing and Spatial Information Science, Vol. XXXVIII, Pt. 8, 2010, pp. 110-115. 


\section{Abbreviations}

\section{Notation}

The following symbols were used in this technical note:

A cross-sectional area

$B \quad$ channel width

$F_{r} \quad$ Froude number

$H \quad$ cross-sectionaly averaged channel depth

$Q \quad$ discharge

$Q_{s} \quad$ suspended sediment load

$S \quad$ water-surface slope

Ss $\quad$ submerged specific gravity

SSC suspended sediment concentration
$U \quad$ cross-sectionaly averaged velocity

$d_{s} \quad$ sediment grain size

$g \quad$ gravity

$n \quad$ Manning's roughness coefficient

$\Delta \quad$ dune height

$\lambda$ dune wavelength

$\gamma_{w} \quad$ specific weight of water

$v \quad$ kinematic viscosity of water

$\rho \quad$ density of water

$\tau_{b} \quad$ bed shear stress

$\theta \quad$ Shield's dimensionless parameter 